\title{
Application of intelligent anchor cable axial force monitoring system in foundation pit support engineering
}

\author{
HUANG Zheng-jun ${ }^{1, *}$, ZHANG Lei ${ }^{1}$, JIAO Shen-hua ${ }^{2}$, LIU Yu ${ }^{1}$, ZHANG Dong ${ }^{1}$, ZHANG Liang ${ }^{1}$ \\ ${ }^{1}$ School of Civil and Resource Engineering, University of Science \& Technology Beijing, Beijing 100083, China \\ ${ }^{2}$ Survey and Design Institute of China North Industries, Beijing 100053, China
}

\begin{abstract}
Using the self-developed intelligent anchor (cable) axial force monitoring system, real-time online monitoring of the axial force of the prestressed anchor and anchor cable in the foundation pit support structure system is realized. The system has automatic acquisition, wireless transmission, real-time monitoring and other advantages. Through actual engineering application and comparative analysis of traditional methods of monitoring data, it can be seen that the monitoring data is also valid and reliable, and the continuity and difference error of the measured curve is better than the traditional method. The system monitoring data can better reflect the relationship between the support structure stress, deformation and construction process in the foundation pit engineering and provide a strong guarantee for the safe and efficient construction of the foundation pit project.
\end{abstract}

\section{Introduction}

Anchor (cable) anchoring support technology has become the main form of engineering support for mine tunnels, slopes, and foundation pits. In the foundation pit, supporting structures using underground continuous wall or reinforced concrete row piles, prestressed anchors and anchor cables have been widely used. Especially in the process of excavation and support construction of deep and large foundation pits, early warning and forecasting of the foundation pits before they are destroyed is for avoiding major engineering safety accidents, which is an extremely important part of the construction process. Therefore, the safety monitoring of supporting structures is important. In particular, long-term effective prestress monitoring of anchors and cables is the key to the success or failure of foundation pit anchorage support and construction safety ${ }^{[1,2]}$.

Many scholars, engineers and technicians have been devoted to study and solve safety monitoring work in anchors, anchor cables and other supporting structures, and have also achieved many results. Such as Chen Jing [3] proposed that the FBG anchor stress meter can be applied to the monitoring of tunnel surrounding rock strains and achieved good results; Xu Jingchun [4] proposed a monitoring method of stripping temperature on the anchor (cable) axial force, which has improved the accuracy of judging the slope deformation and destruction; Dou Chuanhao ${ }^{[5]}$ has studied a hammer acoustic method for monitoring the axial force of anchors against mine anchors; Zhang Wenhong [6] designed a method based on the new real-time monitoring system for anchor tension in the LabWindows CVI development platform, which enables real-time monitoring of the anchoring support parameters. Zhang Lilan et al. ${ }^{[7]}$ introduced the axial force monitoring method for prestressed anchors in deep foundation pit support and implemented monitoring analysis; Zhang Qinxi et al. ${ }^{[8]}$ studied the axial force variation of anchors in different rows of anchor rods by monitoring the axial force of anchor rods in Wangjing Foundation; Zhou Qunhua et al. ${ }^{[9]}$ used anchor cable dynamometers to monitor the stress damage of the anchor cables of anchor cable reinforced prestressed retaining wall, and the long-term stress damage and influencing factors of the anchor cable were analyzed; Yibo et al. ${ }^{[10]}$ conducted a long-term monitoring and analysis of the prestress of the anchor cable of the hydropower station and summarized the influence factors of the prestress damage and made a predicted value.

The above research results and other scholars, technicians provide important reference for the study of the axial force monitoring of prestressed anchor rod anchor cables in the foundation pit support structure. However, the existing monitoring equipment used in the foundation pit often requires active power supply or hydraulic equipment, which has disadvantages such as the need to lay power supply wires, complex structures, and large volumes, which is detrimental to the safety management and large-scale use of construction sites ${ }^{[11-}$ 15]. In this paper, a self-developed and designed intelligent anchor (cable) axial force monitoring system is adopted to automatically, wirelessly and in real time monitor the prestressed anchors (cables) in the foundation pit supporting system to ensure the construction of foundation pits and other projects safe and efficient. 


\section{Intelligent Anchor (Cable) Axial Force Monitoring System}

The intelligent anchor (cable) monitoring system is mainly composed of a force measuring sensor, a data acquisition and transmission system, a monitoring substation, a monitoring terminal and monitoring software. The entire system can achieve low power consumption, automatic timing or trigger acquisition, data wireless transmission, real-time online monitoring and data analysis, query, storage and other functions.

The force measuring sensor adopts the full-bridge differential circuit electrical measurement principle, which has the advantages of high sensitivity, elimination of nonlinear errors, and temperature compensation compared with other bridge methods ${ }^{[16]}$. The principle of electrical measurement is shown in Figure 1, and according to its principle, there are dynamometer and anchor cable dynamometers, as shown in Figure 2.

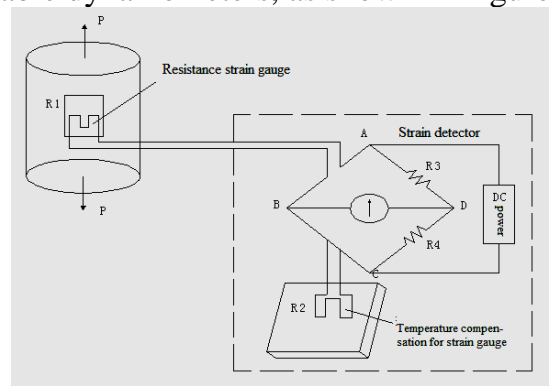

Figure 1 Dynamometer electric measurement schematic diagram

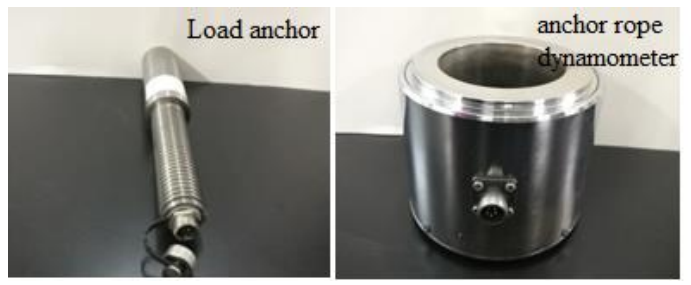

Figure 2 Force measuring anchor and anchor dynamometer

The data acquisition and transmission system mainly include: intelligent data processing chip, wireless data transmission module, wireless data transmission module, wireless data repeater, and network coordinator. The collected large amount of data can be converted into digital signals in real time and sent to monitoring substations in a wireless method to achieve real-time automatic acquisition and wireless transmission functions. The system is equipped with a lithium battery self-powered system, and its low power consumption features can be continuously used in more than 1 year. Its data acquisition and wireless transmission are illustrated in Figures 3 and 4.

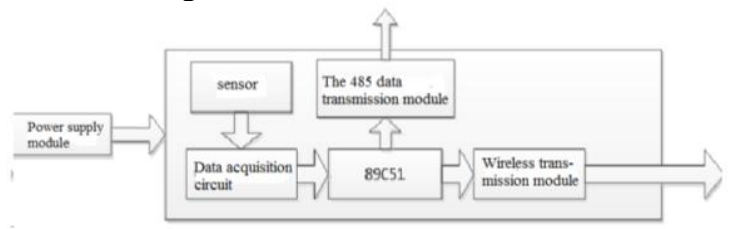

Figure 3 Data collection diagram

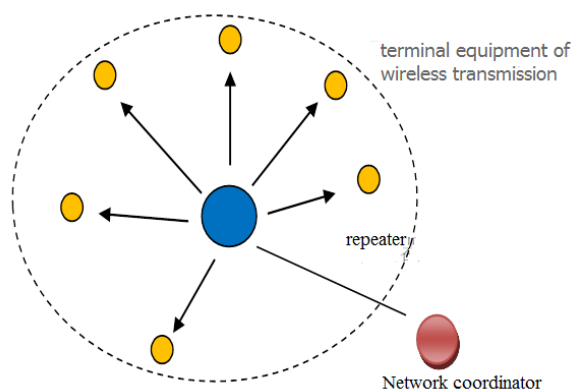

Figure 4 Wireless data transmission diagram

The monitoring substation mainly includes a wireless data receiving, transmitting module (GPRS) and a data communication interface, which needs to use $220 \mathrm{~V}$ active power supply, and is generally arranged in the project department office. The monitoring terminal includes a computer client and a mobile terminal of the mobile phone APP. Through downloading and installing monitoring software, the monitoring terminal can realize real-time data monitoring and online publishing functions.

Monitoring software uses VC++ language to develop and design on Windows operating platform. Its program structure includes several modules such as system setting, data communication, data query, data processing and data maintenance. The embedded data processing module can use the adjustment method to automatically process singular point data in the monitoring data. Monitoring software interface as shown in Figure 5.

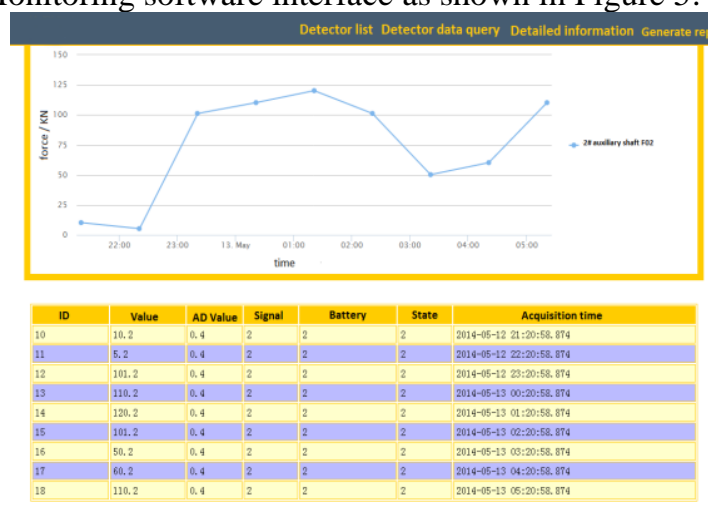

Figure 5 Monitoring system software interface

\section{Examples of Engineering Application}

\subsection{Engineering background}

The foundation pit project of a construction project consists of several pits of different depths, with depths of $-16.23 \mathrm{~m},-10.53 \mathrm{~m},-6.93 \mathrm{~m}$, and $-6.30 \mathrm{~m}$. The site strata can be divided into artificial accumulation layers and quaternary sediment layers. The soil properties mainly consist of sandy silt, silty silt and silty clay, and the depth of excavation is not affected by groundwater. The monitoring area is mainly located on the west side and the south side of the foundation pit. The design support structure is a supporting system that combines the upper mesh anchoring spray with the lower pile anchor support. 
According to the site conditions, the anchor cable axial force intelligent monitoring 3-sections were set up, namely I-I, II-II, and III-III. Each section was arranged along the waist beam with 1 measurement point. Among them, the waist beam of the first and third sections of IIIIII section were not arranged, and the total was 7 measurements. Points and measuring plane layout and section are shown in Figure 6-7. The layout of measuring points in each section is shown in Table 1.

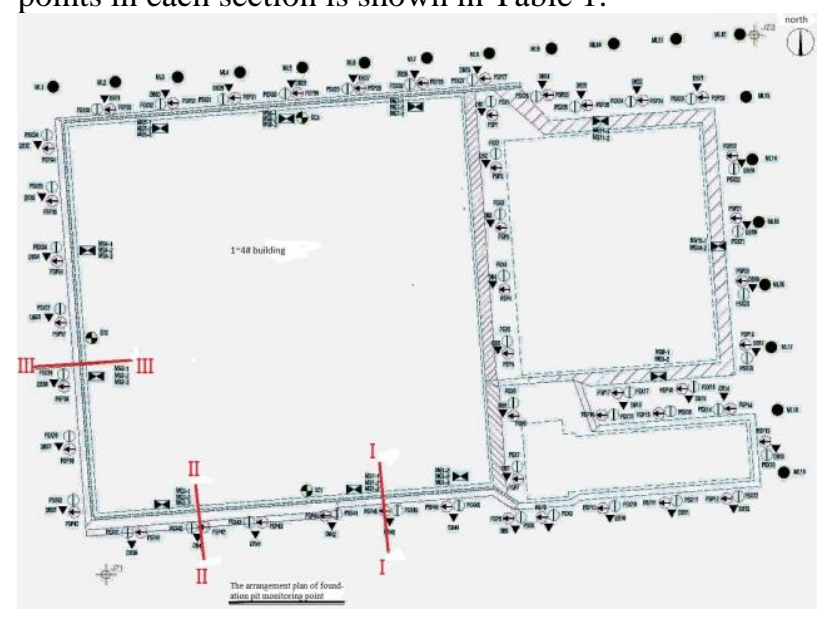

Figure 6 Foundation anchor cable axial force monitoring floor plan

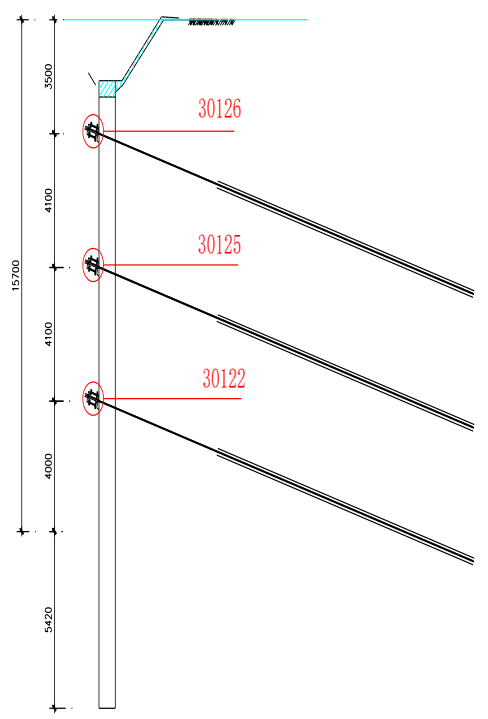

$\underline{\text { II-II Support section }}$

Figure 7 Anchor cable axial force monitoring profile

Another third-party monitoring department adopts traditional detection methods to regularly check the axial force of some anchor cables to achieve the purpose of controlling the construction quality. It can also be compared with the data monitored by the intelligent cable monitoring system to facilitate the verification of the reliability of the monitoring data and the effective and reliable process control and safety monitoring of the intelligent cable monitoring system. The test point distribution is shown in Table 2. Intelligent anchor cable monitoring equipment and traditional equipment on-site layout shown in Figure 8, in which the intelligent anchor rope measuring points were wrapped with insulation cotton, the traditional equipment is wired, and monitoring data reads manually every 2-3 days.

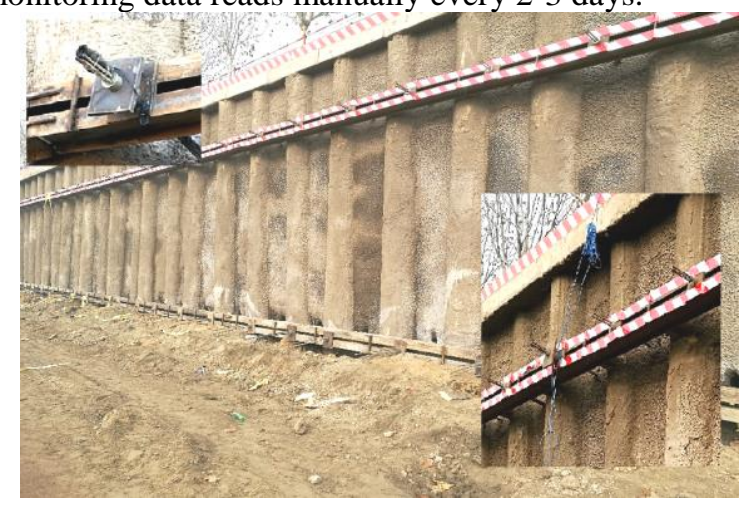

Figure 8 Intelligent anchor cable and traditional monitoring and measurement site scene photos

Table 1 Detailed table of intelligent anchor cable force monitoring and measuring point arrangement

\begin{tabular}{cccccc}
\hline No. & $\begin{array}{c}\text { I-I } \\
\text { Section }\end{array}$ & $\begin{array}{c}\text { II-II } \\
\text { Section }\end{array}$ & $\begin{array}{c}\text { III-III } \\
\text { Section }\end{array}$ & $\begin{array}{c}\text { Monitoring } \\
\text { time }\end{array}$ & Remark \\
\hline 1 & 30128 & 30126 & - & $11.28-3.24$ & $\begin{array}{c}\text { First waist } \\
\text { beam } \\
\text { beam waist } \\
2\end{array}$ \\
30123 & 30125 & 30121 & $12.4-3.24$ & $\begin{array}{c}\text { Second wam } \\
\text { beam } \\
\text { The third } \\
\text { waist beam }\end{array}$ \\
\hline
\end{tabular}

Table 2 Third-party anchor cable axial force measuring point layout table

\begin{tabular}{ccccc}
\hline No. & $\begin{array}{c}\text { South side of } \\
\text { foundation } \\
\text { pit }\end{array}$ & $\begin{array}{c}\text { North side of } \\
\text { foundation pit }\end{array}$ & $\begin{array}{c}\text { West side of } \\
\text { foundation pit }\end{array}$ & Remark \\
\hline 1 & ZL3 & ZL2 & ZL1 & $\begin{array}{c}\text { First waist } \\
\text { beam } \\
\text { becond waist } \\
\text { beam } \\
2\end{array}$ \\
ZL6 & ZL5 & ZL4 & $\begin{array}{c}\text { The third } \\
\text { waist beam }\end{array}$ \\
\hline
\end{tabular}

Explanation: The western measuring point is close to the III-III section, and the south measuring point is located in the middle of the I-I and II-II sections.

\subsection{Monitoring Results}

According to the site construction process and the installation time of the measuring point, the monitoring time is shown in Table 1. The final monitoring of all the measuring points was completed until the excavation of the foundation pit on 2017.3.24. Part of the monitoring data of the measuring points is shown in Figure 9-11. The independent monitoring results of third parties are shown in Figure 12. 


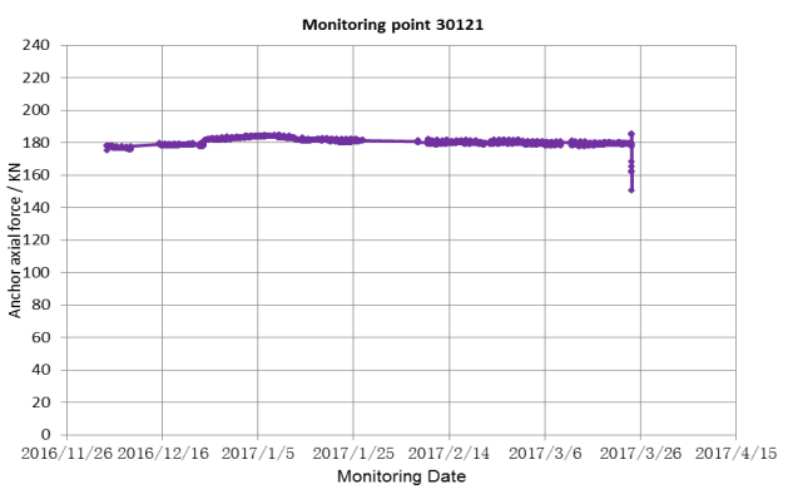

Figure 9 Results of 30121 monitoring point

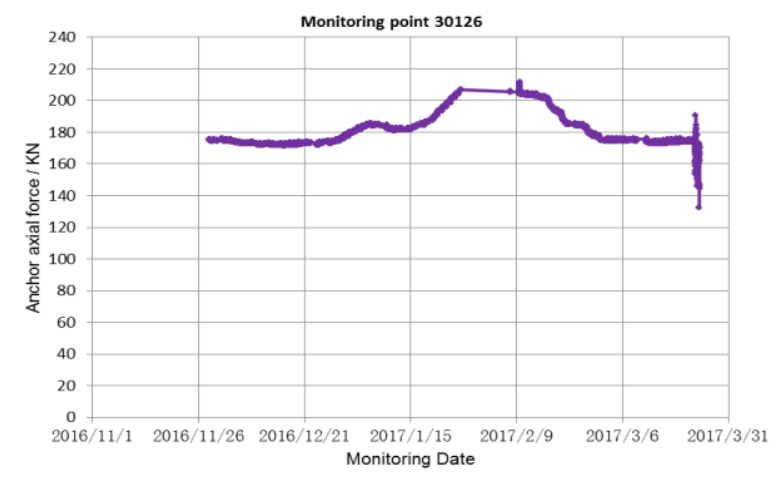

Figure 10 Results of 30126 monitoring point

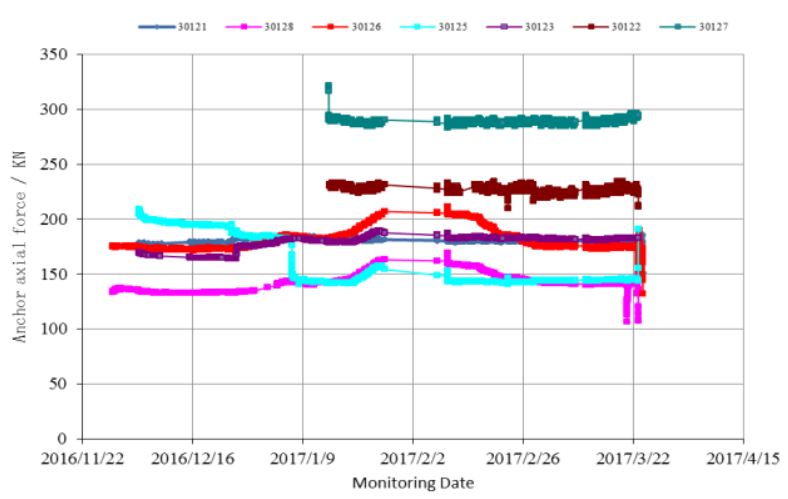

Figure 11 Overall monitoring results of 7 monitoring points

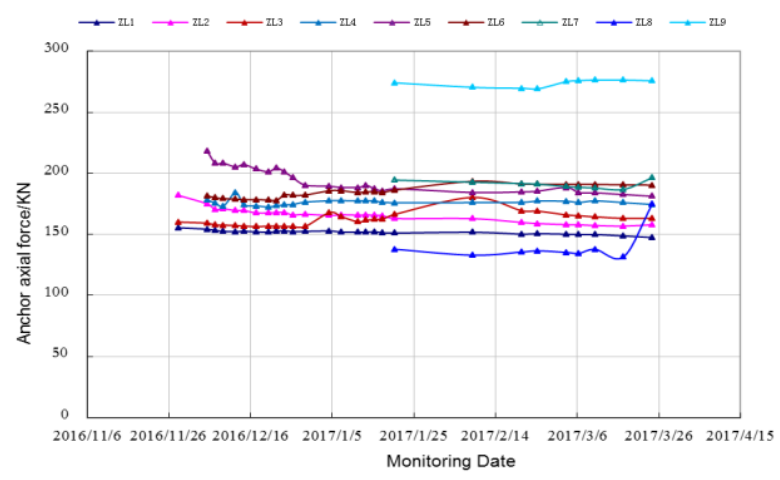

Figure 12 Third-party axial force monitoring results

\subsection{Data Analysis}

Considering that the 30121-measuring point is arranged on the second waist beam of the III-III section on the west side of the foundation pit, and the third-party independent monitoring point ZL4 is also located on the third waist beam on the west side, which is close to the 30121-measuring point. Considering the close distance to the area, the influence of soil stress and engineering disturbance should be approximately the same. So, the 30121-measuring point is taken as an example for detailed analysis. The comparison between the intelligent 30121-monitoring point and the third-party ZL4-monitoring point data is shown in Figure 13.

From Figures 11 to 12, we can see that except 30122 and 30127 measuring points, the axial force of the anchor cable at the other 5 measuring points shows a certain regularity change with time, and the axial force varies with the construction process and the location of the measuring points to rise or fall regularly, which is basically consistent with the rules of third-party monitoring data. The reason is that the 30122 and 30127 measuring points are located in the third waist beam, and like ZL7 ZL9, they are no longer affected by the excavation unloading of the soil and the disturbance of the engineering construction, showing a basically stable state. The other 5 measuring points and ZL1 ZL6 are arranged on the first and second waist beams, and the axial force of the anchor cable shows different trends with excavation unloading. The 30128 and 30126 measuring points are located in the first waist beam, with a slight decrease in axial force with the third excavation, and then followed by the fourth excavation, but with a clear upward trend, similar to ZL1 and ZL4. 30121 and 30125 are located in the second waist beam, which shows a downward trend along with the third and fourth excavations, especially the 30125-measuring point is more obvious, which is similar to ZL2 and ZL5.

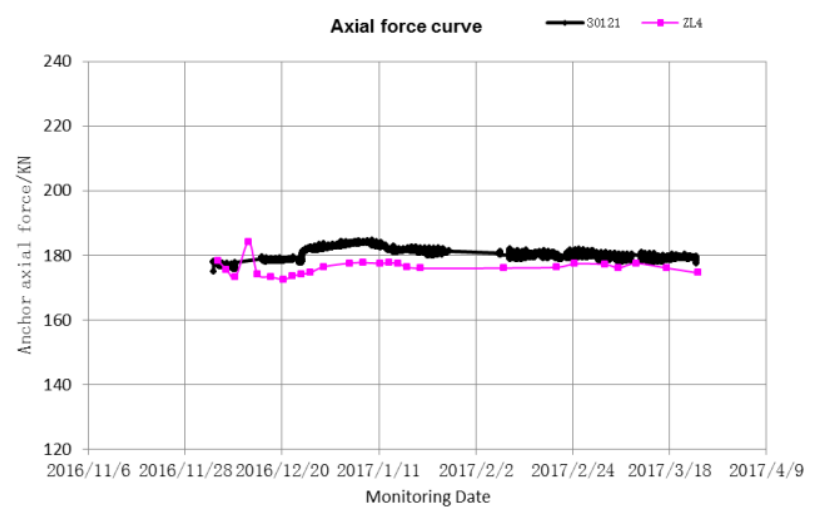

Figure 4 Axial force comparison between 30121 measuring point and ZL4 measuring point 


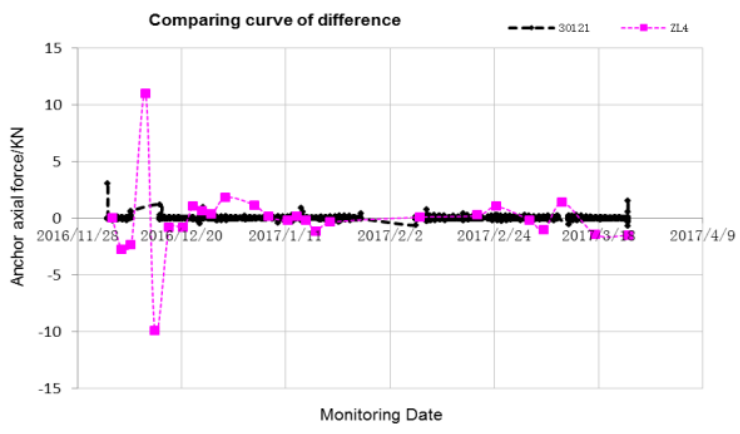

Figure 5 Axial force difference curve

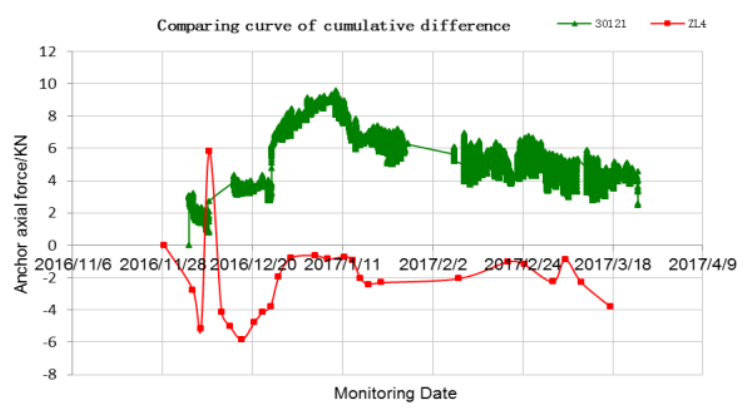

Figure 6 Axial force cumulative difference comparison curve

It can be seen from Figure 13 that the 30121 and ZL4 installation areas are close, and the axial force measured varies with the prestressed tension value, but the variation rules are basically the same, and both are significantly reduced with the fourth excavation unloading, and then they levelled off. From Figure 14, we can see that the difference curve obtained by the intelligent 30121-measurement point is significantly better than the curve obtained by the third-party traditional method. The main reason is that the traditional monitoring method collects the readings manually at a longer period, and the intermediate process will miss many key node data, and the error increases. In Figure 15, the difference in axial force of different anchors is different, but the cumulative difference law obtained by the two monitoring methods is basically the same, and the continuity of the curve obtained by the intelligent monitoring method is better.

\section{Conclusions}

(1) Using the intelligent anchor cable axial force monitoring system to monitor the anchor cable axial force in the foundation pit supporting structure, the system has the characteristics of low power consumption, adjustable timing acquisition, data wireless transmission, etc., so that the monitoring data can be realized real-time online collection, construction management departments can view the support status in real time online to evaluate the safety status of the foundation pit slope, and it achieves wireless and power-free acquisition at the same time, which brings great convenience for on-site construction management.

(2) Through using the intelligent anchor cable axial force monitoring system in monitoring the anchor cable axial force in the foundation pit supporting structural system and comparing it with the data obtained by a third party using the traditional regular manual acquisition method, the result proves that the system has measured the axial force of the anchor cable is more reliable and more effective than conventional methods.

(3) Comparing the measured data of the intelligent anchor cable axial force monitoring system with the traditional method, it can be seen that the data obtained by adopting the new intelligent monitoring method is not only effective and reliable, but also the continuity of the measured value curve and the error value range are obviously better than the traditional method.

\section{References}

1. K. H. HU. A Dissertation Submitted to Zhejiang University of Technology for the Degree of Master of Engineering. Zhejiang University of Technology, (2010)

2. C. L. CHEN, S. H. YE, Y. P. ZHU. Application and monitoring analysis of combined supporting system by prestressed anchors and soil nails for a deep excavation in Lanzhou. Chinese Journal of Geotechnical Engineering, 34(S):484-489( 2012)

3. J. Chen, Y. Ding, K. M. Zhou, L. G. Li, H. Cheng. Research and application of FBG bolt stress meter in tunnel safety monitoring. Geotechnical Investigation \& Surveying, 44(12):48-51( 2016)

4. J. C. XU, J. P. YU, L. J. WU, Z. R. YANG. Analysis of monitored axial force of anchor in the absence of temperature influence. Journal of Yangtze River Scientific Research Institute , 34(01):81-86( 2017)

5. C. H. DOU, L. P. ZHAO, Y. W. LIANG. Study on device of monitoring axial force of rock bolt by Hammering Acoustics. Coal Technology, 35(04):273-276(2016)

6. W. H. ZHANG, H. J. ZHANG, Q. H. GUO. Mining bolts tension monitoring system of based on LabWindows CVI development platform. Colliery Mechanical \& Electrical Technology , (02):46(2010)

7. L. L. ZHANG. Monitoring and analysis of the prestressed anchor in deep foundation pit supporting structure. Academic Essays of Jilin Civil Construction Society in 2011, Jilin civil construction society, 4(2011)

8. Q. X. ZHANG, X. LIU. Monitoring study on anchor tension of deep excavation engineering of Wangjing A1-C-4 Project. Chinese Journal of Geotechnical Engineering, 36(S2):466-470(2014)

9. Q. H. ZHOU, S. W. YAN, W. D. DENG, L. Q. SUN. Application of Tendon Dynameter in Monitoring Reinforcement of Retaining Wall Using Prestressed Tendons. Journal of Highway and Transportation Research and Development, 30(03):52-58(2013) 
10. B. YI, Y. F. WANG, Q. LV, Q. WANG. Monitoring and Analysis on Anchor Cable Prestress of Gate Pier, Shuhe Hydropower Station. Northwest Hydropower, (6):112-116(2017)

11. D. Y. WANG, H. X. ZHOU, X. C. LIANG. Monitoring and Early-warning of Rock Slope Anchor Cable Stress on the Expressway. CONSTRUCTION TECHNOLOGY, 46(S):200203(2017)

12. M. Y. ZHAO, Y. Q. CHENG. Simulation experimental plat form for monitoring mine anchor cables stress based on ZigBee. Experimental Technology and Management, 31(08):159-163(2014)

13. Z. M. QI. Monitoring analysis on a cable supporting foundation pit. SHANXI ARCHITECTURE, 37(29):85-86(2011)

14. Z. H. YANG, Z. X. GUO. Monitoring analysis of pre-stressed load of anchor cables for deep excavations. Chinese Journal of Geotechnical Engineering, 34(S1):145-148( 2012)

15. Y. Z. GONG, H. E. WU, Z. G. YUAN. Analysis on Monitoring of Anchor's Axial Force of Piles and Anchor Support System in Deep Foundation Pit. Prospecting engineering (geotechnical drilling and digging engineering), 33 (10) 6:66-68(2012)

16. L. ZHANG, J. H. KOU, M. L. DOU, Z. J. HUANG. Monitoring and research on surrounding rock stress in roadway under the influence of goaf. Journal of Safety Science and Technology, 11(08):33-39(2015) 